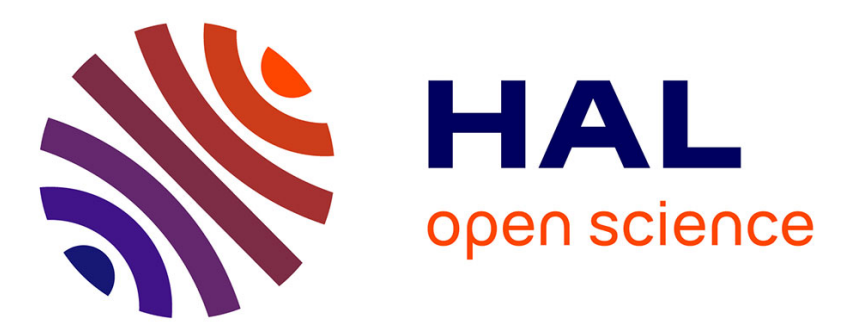

\title{
Optimization of the number of transportation devices in a flexible manufacturing system using event graphs
}

\author{
Jean-Marie Proth, Nathalie Sauer, Xiaolan Xie
}

\section{To cite this version:}

Jean-Marie Proth, Nathalie Sauer, Xiaolan Xie. Optimization of the number of transportation devices in a flexible manufacturing system using event graphs. [Research Report] RR-2359, INRIA. 1994, pp.18. inria-00074318

\section{HAL Id: inria-00074318 \\ https://hal.inria.fr/inria-00074318}

Submitted on 24 May 2006

HAL is a multi-disciplinary open access archive for the deposit and dissemination of scientific research documents, whether they are published or not. The documents may come from teaching and research institutions in France or abroad, or from public or private research centers.
L'archive ouverte pluridisciplinaire HAL, est destinée au dépôt et à la diffusion de documents scientifiques de niveau recherche, publiés ou non, émanant des établissements d'enseignement et de recherche français ou étrangers, des laboratoires publics ou privés. 


\section{Optimization of the number of transportation devices in a flexible manufacturing system using event graphs}

Jean-Marie PROTH - Nathalie SAUER

Xiaolan XIE

\section{$\mathrm{N}^{\circ} 2359$}

Septembre 1994

PROGRAMME 5

\section{apport}

derecherche

arand and 
Les rapports de recherche de l'INRIA INRIA research reports sont disponibles en format postscript sous ftp.inria.fr (192.93.2.54) are available in postscript format ftp.inria.fr (192.93.2.54)

si vous n'avez pas d'accès ftp if you haven't access by fip la forme papier peut être commandée par mail : we recommend ordering them by e-mail : e-mail : dif.gesdif@inria.fr c-mail : dif.gesdif@inria.fr (don't forget to mention your postal address).

(n'oubliez pas de mentionner votre adresse postale).

par courrier : by mail :

Centre de Diffusion Centre de Diffusion

INRIA INRIA

BP 105 - 78153 Le Chesnay Cedex (FRANCE) BP 105 - 78153 Le Chesnay Cedex (FRANCE) 


\title{
OPTIMISATION DU NOMBRE D'UNITÉS DE TRANSPORT DANS UN A TELIER FLEXIble À L'AIDE des GRAPHES d'EVÉNEMENTS
}

\author{
Jean-Marie PROTH*, Nathalie SAUER**, Xiaolan XIE**
}

\section{Résumé:}

Une étape importante dans la conception d'ateliers flexibles qui utilisent des ressources de transport à trajets variables est la définition du nombre de ces ressources de transport nécessaires pour atteindre une productivité donnée. Une méthode utilisée pour déterminer ce nombre consiste à considérer un ensemble de scénari réalistes, à déterminer le nombre de ressources de transport nécessaires pour chaque scénario, et à garder finalement le nombre minimal trouvé.

Dans cette publication, nous proposons une approche par séparation et évaluation pour définir le nombre minimal de ressources de transport nécessaires pour un scénario donné. Cette approche est basée sur une modélisation à l'aide des graphes d'événements.

\section{Mots clefs:}

Ateliers flexibles, Systèmes de transport, Réseaux de Petri, Graphes d'Événements, Véhicules filo-guidés, Véhicules radio-guidés, Optimisation, Modélisation.

* INRIA-Lorraine, Technopôle Metz 2000. 4 rue Marconi, 57070 Metz, FRANCE, et Institute for Systems Research, University of Maryland, College Park, MD 20742, USA

** INRIA-Lórraine, Technopôle Mełz 2000, 4 rue Marconi, 57070 Metz., FRANCE 


\title{
OPTIMIZATION OF THE NUMBER OF TRANSPORTATION DEVICES IN A Flexible MANUfaCturing SyStem USING Event GRAPHS
}

\author{
Jean-Marie PROTH*, Nathalie SAUER**, Xiaolan XIE**
}

\begin{abstract}
:
An important step when designing a Flexible Manufacturing System (FMS) using Automated Guided Vehicles (AGVS) is the definition of the number of AGVs to be used in order to reach a given productivity. A way to define this number is to consider several scenari, to define the minimal number of AGVs required by each scenario, and to keep the maximal of these numbers.

In this paper, we propose a Branch and Bound (B\&B) approach to define the minimal number of AGVs require for a scenario. This approach is based on an Event Graph (EG) formulation.
\end{abstract}

\section{Keywords:}

Flexible Manufacturing Systems, Transportation Systems, Petri nets, Event Graphs, Automated Guided Vehicles, Optimization, Modelling.

* INRIA-Lonaine, Technopôle Metz 200(0, 4 rue Marconi, 57070) Metz, FRANCE, and Institute for Systems Research, University of Maryland, College Pak, MD 20742, USA

** INRIA-Lorraine, Technopôle Metz 2000, 4 rue Marconi, 57070) Metz, FRANCE 


\section{INTRODUCTION}

One of the decisions to be made when designing Flexible Manufacturing Systems (FMSs) using Automated Guided Vehicles (AGVs) concerns the number of AGVs to be used in the FMS in order to meet the customer requirements. At this point of the design process, the manufacturing resources have already been selected. The goal is, of course, to minimize the number of AGVs since they are usually very expensive, and since both the complexity of the management system and the level of the Work-In-Process (WIP) increase with the number of vehicles. A usual way to solve this problem is to consider several scenari, each scenario being a set of customer requirement ratios and, for each scenario, to minimize the number of $A G V s$ required to maximize the productivity of the system. The number of AGVs needed is the maximum among the previous minima. Note that the scenari selected are supposed to be representative of the future customer requirement ratios. Furthermore, the maximal productivity obtained for each scenario should be equal to or greater than the customer requirements, otherwise at least some of the manufacturing resources would be overloaded, which would require to reconsider the choice of these resources.

This paper addresses the problem of minimizing the number of AGVs while reaching a given productivity when the ratios of the customer requirements are known. In that case, the control of the system is expressed by a sequence of part types associated to each manufacturing resource. These sequences reflect the required ratios. Such a sequence, called input sequence, defines the order the product types are manufactured by the corresponding resource. It has been showed in [4] and [5] that such a system can be modelled as a strongly connected Event Graph (EG) and that the problem to be solved is a Mixed Linear Programming (MLP) problem in which the integer variables are binary variables.

Several efficient heuristic approaches have been proposed in the past. In this paper, we propose an approach which leads to the optimal solution. This paper is organized as follows.

The problem is presented in Section 2. Another formulation, used to develop the Branch and Bound approach, is introduced in Section 3. The B\&B approach is presented in Section 4. The upper bound required by the $B \& B$ approach is obtained using the so-called "Adjustment Algorithm" presented in [5]. This algorithm is given in Section 5. Section 6 is devoted to the computation of the lower bound. The B\&B algorithm is summarized in Section 7. The algorithm is applied to a FMS in Section 8, and Section 9 is a conclusion.

The reader is supposed to be aware of the basics of Petri nets and, in particular, of the properties of EG which can be found in the above references as well as in [1], [2], [3, [4] and [6]. 


\section{Presentation of the Problem}

The productivity of a FMS can be expressed in terms of the cycle time of its strongly connected EG model: the smaller the cycle time, the greater the productivity. Reaching a given productivity of a FMS is thus equivalent to reach a given cycle time $C$ for its strongly connected EG model. Furthermore, minimizing the number of AGVs is equivalent to minimize a linear combination of the place markings, the coefficients of the linear combination heing the elements of a p-invariant. As a consequence, the function to be minimized is invariant if we replace a given marking $\mathrm{M}_{0}$ of the strongly connected $E G$ by any marking $M$ derived from $M_{0}$ (we denote it by $M \in R\left(M_{0}\right)$ ) by firing a sequence of transitions.

According to the previous remarks, the problem at hand consists of finding an initial marking $\mathrm{M}_{0}$ which:

Minimizes tU.Mo

s.t.

$\pi\left(\mathrm{M}_{0}\right) \leq \mathrm{C}$

and $M_{0}(p) \in\{0,1,2\}$ for any $p \in P$, set of places

where $U$ is a p-invariant and $\pi\left(\mathrm{M}_{0}\right)$ is the cycle time of the strongly connected $E G$ when the transitions are fired as soon as they are enabled, starting from $M_{0}$. Constraints $M_{0}(p) \in\{0,1,2\}$ have been proven in Laftit et al. [5].

It was proven in Chretienne [2] that:

$$
\pi\left(\mathrm{M}_{0}\right)=\operatorname{Min}_{\gamma \in \Gamma}\left[\mu(\gamma) / \mathrm{M}_{0}(\gamma)\right]
$$

where $\Gamma$ is the set of elementary circuits of the strongly connected $E G, \mu(\gamma)$ is the sum of the firing times of the transitions belonging to $\gamma$, and $\mathrm{M}_{0}(\gamma)$ is the number of tokens in the places belonging to $\gamma$ when $\mathrm{M}_{0}$ applies.

Thus, constraints (2) can be rewritten as:

$$
\mathrm{M}_{0}(\gamma) \geq\lceil\mu(\gamma) / \mathrm{C}\rceil \text { for any } \gamma \in \Gamma
$$

where $\lceil\mathrm{a}\rceil$ is the smallest integer greater than or equal to a.

Inequalities (4) can further he rewritten as:

$$
\text { D. } \mathrm{M}_{0} \geq \mathrm{B}
$$

where:

$d_{i j}= \begin{cases}1 & \text { if place } p_{j} \text { belongs to the } \mathrm{i}-\text { th elementary circuit } \\ 0 & \text { otherwise }\end{cases}$

for $i=1$ to $r$ and $j=1$ to $|P|$ ( $r$ is the number of elementary circuits and $|P|$ the number of places),

$\mathrm{B}=\left[\mathrm{b}_{1}, \ldots, \mathrm{b}_{\mathrm{r}}\right]$, with $\mathrm{b}_{\mathrm{i}}=\left\lceil\mu\left(\gamma_{\mathrm{i}}\right) / \mathrm{C}\right\rceil, \gamma_{\mathrm{i}}$ being the $\mathrm{i}$-th elementary circuit. 
The problem at hand, referred to as $\boldsymbol{P}_{0}$, becomes:

find the initial marking $\mathrm{M}_{0}$ which:

Minimizes U.M $_{0}$

s.t.

$$
\begin{aligned}
& \text { D. } \left.M_{0}\right) \geq B \\
& \text { and } M_{0}(p) \in\{0,1,2\}, \forall p \in P
\end{aligned}
$$

This problem is an integer linear programming problem whose variables are the initial numbers of tokens in each place. The drawback of this formulation is that the number of constraints (5) is equal to the number of elementary circuits, which is unpredictable and usually very large. It is the reason why another formulation has been proposed by Laftit et al. [5]. This formulation is partially based on the results obtained by Ramchandani [8] and Ramamoorthy [7].

This problem, introduced in Laftit et al. [5], is referred to as $\boldsymbol{P}_{1}$ in the remainder of the paper and is expressed as follows:

\section{Minimize IU.M $M_{0}$}

s.t.

$$
\begin{aligned}
& S_{\mathrm{op}}(1)+\theta_{\mathrm{op}} \leq \mathrm{S}_{\mathrm{po}}(1)+C \cdot \mathrm{M}_{0}(\mathrm{p}), \forall \mathrm{p} \in \mathrm{P} \\
& \mathrm{S}_{\mathrm{t}}(1) \in\left(-\theta_{\mathrm{t}}, \mathrm{C}-\theta_{\mathrm{t}}, \forall \mathrm{t} \in \mathrm{T}\right. \\
& \mathrm{M}_{0}(\mathrm{p}) \in\{0,1,2\}, \forall \mathrm{p} \in \mathrm{P}
\end{aligned}
$$

where $T$ is the set of transitions, ${ }^{0} p$ (resp. $p^{0}$ ) is the input (resp. output) transition of place $p, S_{t}(1)$ is the instant at which transition $t$ starts firing for the first time, and $\theta_{t}$ is the firing time of transition $\mathrm{t}$.

The number of variables to be defined when solving $\boldsymbol{P}_{1}$ is $|\mathrm{P}|+|\mathrm{T}|$ ( $|\mathrm{P}|$ integer variables $M_{0}(p)$ and $|T|$ real variables $\left.S_{t}(1)\right)$. This should be compared to the $|P|$ variables $M_{0}(p)$ to be defined when solving $\boldsymbol{P}_{0}$. But the number of constraints (6) and (8) is equal to $2|\mathrm{P}|+|\mathrm{T}|$ when solving $\boldsymbol{P}_{1}$, while the number of constraints (5) is unpredictable when solving $\boldsymbol{P}_{0}$. Thus, $\boldsymbol{P}_{1}$ is $a$ priori easier to solve than $\boldsymbol{P}_{0}$. The following result, due to Laftit et al. [5], links the solutions of $\boldsymbol{P}_{0}$ and $\boldsymbol{P}_{1}$.

\section{Result 1:}

The restriction of the optimal solution of $\boldsymbol{P}_{1}$ to $\left\{\mathrm{M}_{0}(\mathrm{p})\right\}_{\mathrm{p} \in \mathrm{P}}$ is an optimal solution of $\boldsymbol{P}_{0}$.

Note also that, due to relation (6), the solution obtained is periodic.

In the approach present in this paper, we aim at solving $\boldsymbol{P}_{1}$ for the EG model of an FMS. 


\section{A NEW Formulation}

The purpose of this section is to provide an alternative formulation of problem $\boldsymbol{P}_{1}$ which will be used to develop the Branch and Bound approach.

We first prove that the solution space of problem $\boldsymbol{P}_{1}$ can be reduced by using some properties of the optimal solutions.

\section{Result 2:}

Problem $\boldsymbol{P}_{1}$ is equivalent to problem $\boldsymbol{P}_{2}$ defined as follows:

Minimize U.M $M_{0}$

s.t.

$$
\begin{aligned}
& \theta_{\mathrm{op}} \leq \mathrm{S}_{\mathrm{po}}(1)-\mathrm{S}_{\mathrm{op}}(1)+\mathrm{C} \cdot \mathrm{M}_{0}(\mathrm{p})<\mathrm{C}+\theta_{\mathrm{o}} \mathrm{p}, \forall \mathrm{p} \in \mathrm{P} \\
& \mathrm{S}_{\mathrm{l}}(1) \in\left(-\theta_{\mathrm{l}}, \mathrm{C}-\theta_{\mathrm{t}}\right], \forall \mathrm{t} \in \mathrm{T} \\
& \mathrm{M}_{0}(\mathrm{p}) \in\{(0,1,2\}, \forall \mathrm{p} \in \mathrm{P} \\
& \mathrm{M}_{0}(\mathrm{q}) \leq 1+\mathrm{M}_{0}(\mathrm{p}), \forall \mathrm{p}, \mathrm{q} \in \mathrm{P} \text { with } \mathrm{p}^{\mathrm{o}}=\mathrm{q}^{\mathrm{o}}
\end{aligned}
$$

Proof:

Let us first show that any solution $\left\{S_{1}(1), M_{0}\right\}$ satisfying constraints $\left(6^{\prime}\right),(7)$ and (8) also satisfies constraint (9). For this purpose, consider two places $p$ and $q$ such that $\mathrm{p}^{0}=\mathrm{q}^{\mathrm{o}}=\mathrm{t}$.

From constraint $\left(6^{\prime}\right)$,

$$
\text { C.M }(q)<C+\theta_{o q}+S_{o q}(1)-S_{t}(1)
$$

Since $\theta_{\mathrm{q}}(1)-\mathrm{S}_{\mathrm{oq}}(1) \leq \mathrm{C}$,

$$
\text { C.M }(q)<2 C-S_{\mathfrak{l}}(1)
$$

Again from constraint (6'),

$$
-S_{t}(1) \leq-\theta_{o p}-S_{o p}(1)+C . M_{0}(p)
$$

Since $\theta_{o p}+S_{o p}(1)>0$,

$$
-S_{t}(1)<C . M_{0}(p)
$$

Combining (10) and (11), we obtain:

$$
M(q)<2+M_{0}(p)
$$

Since $M(q)$ and $M(p)$ are integers,

$$
M(q) \leq 1+M_{0}(p)
$$

In the remainder of the proof, we establish the equivalence between $\boldsymbol{P}_{1}$ and $\boldsymbol{P}_{2}$ by showing that there exists an optimal solution of $\boldsymbol{P}_{1}$ which satisfies constraint $\left(6^{\prime}\right)$.

Consider an optimal solution $\left\{\mathrm{S}_{\mathbf{l}}(1), \mathrm{M}_{0}\right\}$ of $\boldsymbol{P}_{1}$. Assume that constraint $\left(6^{\prime}\right)$ does not hold for place $p_{1}$, i.e.:

$$
\mathrm{S}_{\mathrm{p}_{1}} \mathrm{o}(1)-\mathrm{S}_{\mathrm{o} \mathrm{p}_{1}}(1)+\mathrm{C} \cdot \mathrm{M}_{0}\left(\mathrm{p}_{1}\right) \geq \mathrm{C}+\theta_{0} \mathrm{p}_{1}
$$

We consider a new marking $M_{1}$ defined as follows:

$$
\mathrm{M}_{1}(\mathrm{p})=\mathrm{M}_{0}(\mathrm{p}) \forall \mathrm{p} \notin \mathrm{p}_{1} \text { and } \mathrm{M}_{1}\left(\mathrm{p}_{1}\right)=\mathrm{M}_{0}\left(\mathrm{p}_{1}\right)-1 \text {. }
$$




\section{Clearly,}

$$
S_{p o(1)}-S_{O_{p}}(1)+C . M_{1}(p) \geq \theta o_{p} \text { for all } p \in P
$$

Furthermore, relation (12) implies that:

$$
\begin{aligned}
\text { C. } M_{0}\left(p_{1}\right) & \geq C+\theta_{o} p_{1}+S_{0 p_{1}}(1)-S_{p_{1} o(1)} \\
& >C+\theta_{o p_{1}} o+\left(-\theta_{o} p_{1}\right)-\left(C-\theta_{p_{1}}\right) \quad \text { (constraint (7)) } \\
& \geq 0
\end{aligned}
$$

Since $M_{0}\left(p_{1}\right)$ is an integer,

$$
M_{0}\left(p_{1}\right) \geq 1
$$

which implies that

$$
0 \leq \mathrm{M}_{0}\left(\mathrm{p}_{1}\right)<\mathrm{M}_{0}\left(\mathrm{p}_{1}\right) \leq 2
$$

These inequalities together with relation (13) show that $\left\{S_{t}(1), M_{1}\right\}$ is a solution to $\boldsymbol{P}_{1}$. Since $\left\{S_{t}(1), M_{0}\right\}$ is an optimal solution to $P_{1}$ and since $1 U \cdot M_{1} \leq \mathbb{U} \cdot M_{0},\left\{S_{t}(1), M_{1}\right\}$ is also an optimal solution to $\boldsymbol{P}_{1}$.

If constraint (6') still does not hold, the above reasoning is repeated until an optimal solution satisfying $\left(6^{\prime}\right)$ is obtained. This solution is clearly an optimal solution to $\boldsymbol{P}_{2}$.

Q.E.D.

Let us notice that constraint (9) is considered in $\boldsymbol{P}_{2}$ event though it is redundant. As can be expected, this constraint can be used to obtain tight bounds when the integrity is relaxed.

Finally, as in [5], we extend the EG model of an FMS such that at least one optimal initial marking assigns at most one token to each place. For this purpose, for each place $\mathrm{p}$ of the model, one additional place $\mathrm{p}^{\prime}$ and one additional transition $\mathrm{t}^{\prime}$ whose firing time is equal to zero are introduced, as shown in Figure 1.

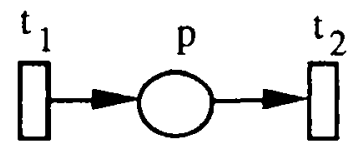

Initial graph

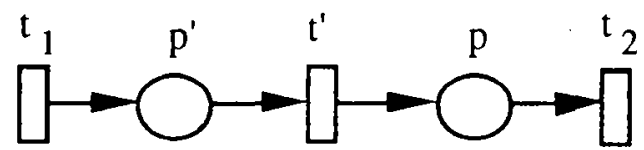

Extended graph

Fig. 1: Extension of the initial graph

In the remainder of this paper, we denote by $\mathrm{P}_{0}$ and $\mathrm{T}_{0}$ the set of initial places and the set of initial transitions and by $P_{s}$ and $T_{s}$ the set of places $p^{\prime}$ and the set of transitions $t^{\prime}$ added to the model. Clearly, in the extended model, there exists an optimal solution such that $\mathrm{M}_{0}(\mathrm{p}) \leq 1$ and $\mathrm{M}_{0}\left(\mathrm{p}^{\prime}\right) \leq \mathrm{M}_{0}(\mathrm{p})$. Thus problem $\boldsymbol{P}_{2}$ becomes problem $\boldsymbol{P}_{3}$ defined as follows:

$$
\text { Min }{ }^{U} \mathrm{U} . \mathrm{M}_{0}
$$

s.t.

$$
\begin{aligned}
& \theta_{\mathrm{Op}^{\prime} \leq} \mathrm{S}_{\mathrm{p}^{\mathrm{o}}}(1)-\mathrm{Sop}_{\mathrm{o}}(1)+\mathrm{C} .\left[\mathrm{M}_{0}(\mathrm{p})+\mathrm{M}_{0}\left(\mathrm{p}^{\prime}\right)\right]<\mathrm{C}+\theta_{\mathrm{Op} \mathrm{p}^{\prime}}, \forall \mathrm{p} \in \mathrm{P}_{0} \\
& \left.S_{\mathrm{t}}(1) \in\left(-\theta_{\mathrm{t}}, C-\theta_{\mathrm{t}}\right], \forall \mathrm{t} \in \mathrm{T}_{0}\right) \\
& \mathrm{M}_{0}(\mathrm{p}), \mathrm{M}_{0}\left(\mathrm{p}^{\prime}\right) \in\{0,1\}, \forall \mathrm{p} \in \mathrm{P}_{0}, \forall \mathrm{p}^{\prime} \in \mathrm{P}_{\mathrm{s}} \\
& \mathrm{M}_{0}\left(\mathrm{q}^{\prime}\right) \leq \mathrm{M}_{0}(\mathrm{p}), \forall \mathrm{p}, \mathrm{q} \in \mathrm{P}_{0} \text { with } \mathrm{p}^{\mathrm{o}}=\mathrm{q}^{\mathrm{o}}
\end{aligned}
$$

The $\mathrm{B} \& \mathrm{~B}$ approach presented latter is based on this formulation. In the following, we denote 
by $\mathrm{P}$ and $\mathrm{T}$ the set of places and the set of transitions of the extended model, i.e. $\mathrm{P}=\mathrm{P}_{0} \cup \mathrm{P}_{\mathrm{S}}$ and $\mathrm{T}=\mathrm{T}_{0} \cup \mathrm{T}_{\mathrm{s}}$.

\section{A BRANCh AND Bound Approach For Solving $\boldsymbol{P}_{3}$}

\section{a. Initializing the Branch and Bound process}

The Branch and Bound $(B \& B)$ approach starts by defining the root of the $B \& B$ tree. For this purpose, we choose a transition $t_{0}$ and we set $S_{t_{0}}(1)=0$ : since the solution we are looking for is periodic, we know that each transition fires at least once on any period of length $C$, and thus we can choose the beginning of such a period at any point in time, and in particular at the instant a given transition starts firing.

In order to increase the efficiency of the algorithm, we choose the transition to such that $\sum_{p \in{ }^{\circ} t_{0}} u_{p}$ is maximal, where $u_{p}$ is the coefficient of the p-invariant $U$ corresponding to $p$.' If several transitions lead to the maximal value, we choose the one which has the maximal number of input places. If several transitions are still candidates, we choose one of them at random.

Since to starts at time 0 , and since a place contains at most one token initially, we set $M_{0}(p)=1$ for $p \in{ }^{0} t_{0}$.

\section{b. Computation of the descendants of a node}

Let us consider, at a given stage of the $B \& B$ process, a node $w$ which has no descendants. Such a node is called a leaf of the $B \& B$ tree. We denote by $P f(w)$ the set of places whose marking has been defined before reaching node $w$. The next step consists of selecting the place $p^{*} \in P \backslash P^{f}(w)$ to be marked next.

The choice of $\mathrm{p}^{*}$ is made according to an order defined on the set of places. In this order, the places belonging to $\mathrm{P}_{0}$ are ordered first ( $\mathrm{P}_{0}$ is the set of initial places). In most of the optimal solutions obtained when considering FMSs, the markings of the places of the initial models (i.e. models not yet extended) are less than or equal to one, which means that, in the extended models, $M\left(p^{\prime}\right)=0$ for $p^{\prime} \in P_{s}$. Thus, it is likely to obtain the optimal solution after just considering the places belonging to $\mathrm{P}_{0}$, which drastically reduces the branches to be explored. This explains the reason why the places of $\mathrm{P}_{0}$ are ordered first. The places of $\mathrm{P}_{0}$ are further ordered in the decreasing order of the corresponding element of the p-invariant $U$. The explanation is straight forward: following this order, the partial values of the objective function grow faster which, in turn, favour sooner decisions not to explore branches. This reduces the number of nodes to take into account, and thus the computation burden.

The order of the places belonging to $\mathrm{P}_{\mathrm{s}}$ (which follows the places of $\mathrm{P}_{0}$ ) is random.

Thus, $\mathrm{p}^{*}$ is the place belonging to $\mathrm{PIP}_{(\mathrm{f})}$ which is ordered first according to the order defined 
above.

Starting from node $w$, we create two descendants $w_{0}$ and $w_{1}$ as shown in Figure 2.

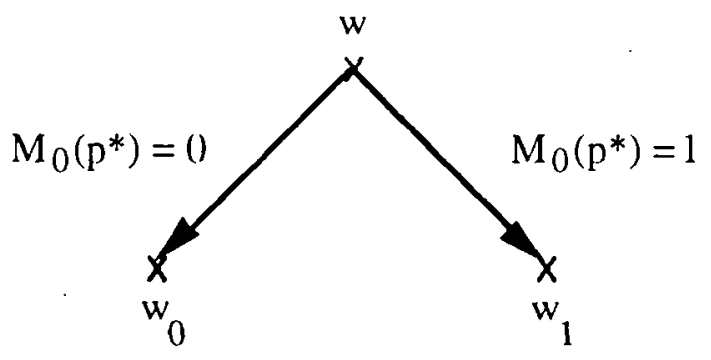

Fig. 2: Descendants of a node w

For the new node $w_{0}$, if $\mathrm{p}^{*}$ is an initial place, i.e. $\mathrm{p}^{*} \in \mathrm{P}_{0}$, according to constraint (17), $\mathrm{M}_{0}\left(\mathrm{q}^{\prime}\right)=0$ for all places $\mathrm{q}^{\prime}$ and such that $\mathrm{q}^{\prime}=\left(\mathrm{p}^{*}\right)^{\mathrm{O}}$. In this case, $\mathrm{Pf}^{\mathrm{f}}\left(\mathrm{w}_{0}\right)=\mathrm{Pf}^{\mathrm{f}}(\mathrm{w}) \cup\left\{\mathrm{p}^{*}\right\} \cup$ $\left\{q^{\prime} / q^{0}=\left(p^{*}\right)^{0}\right\}$. For the new node $w_{1}, P^{f}\left(w_{1}\right)=p^{f}(w) \cup\left\{p^{*}\right\}$.

For $w_{0}$ and $w_{1}$, we compute a lower and an upper bound of the optimal solution, taking into account the places whose marking has been previously fixed. The lower bound is obtained by relaxing the integrity constraint of the markings $\mathrm{M}_{0}(\mathrm{p})$ for $\mathrm{p} \notin \mathrm{Pf}\left(\mathrm{w}_{\mathrm{i}}\right)$ with $\mathrm{i}=0$ or 1 . If the relaxed problem does not have solution, then the node at hand does not contain solution to problem $\boldsymbol{P}_{3}$ and it is a leaf of the global $B \& B$ tree. Otherwise, if the lower bound is greater that the smallest upper bound previously obtained (including the upper bound computed for the current node), then the node at hand is a leat of the global $B \& B$ tree (i.e. no further descendant will be considered starting from this node). Otherwise, two new descendants of this node will be considered, as defined above.

The computation of the upper and the lower bounds is presented in the following sections.

\section{COMPUTATION OF THE UPPER BOUND}

The computation of the upper bound is hased on the Adjustment Algorithm (AA) due to Laftit et al. [5]. Let us briefly recall this algorithm.

\section{a. The Adjustment Algorithm (AA)}

The $\mathrm{AA}$ is a heuristic algorithm which applies to problem $\boldsymbol{P}_{0}$ (i.e. to the initial $\mathrm{EG}$ model). It starts with a feasible solution, that is a solution which verifies constraints (5). It then proceeds iteratively. At each operation, one token is removed from the system as long as the marking remains feasible. The token which is removed is the one which leads to the maximal decrease of the objective function while minimizing the least the degree of freedom of the system.

The degree of freedom of a place $p \in P$ is defined by:

$$
\operatorname{df}\left(M_{0}, p, C\right)=\operatorname{Min}_{\gamma \in \Gamma_{p}}\left(M_{0}(\gamma)-\mu(\gamma) / C\right)
$$


where $\Gamma_{p}$ is the set of elementary circuits which contain $p$, and $\left\lfloor d f\left(M_{0}, p, C\right)\right\rfloor$ is the maximal number of tokens which can be removed from place $\mathrm{p}$ while keeping the cycle time of the system less than $\mathrm{C}$.

The variation of the degree of freedom of the system when removing a token from place $p$ is given by:

$$
\operatorname{Var}(\mathrm{p})=\sum_{q \in \mathrm{P}} \mathrm{u}_{\mathrm{q}}\left[\mathrm{df}\left(\mathrm{M}_{0}, \mathrm{q}, \mathrm{C}\right)-\operatorname{df}\left(\mathrm{M}_{1}, \mathrm{q}, \mathrm{C}\right)\right]
$$

where $u_{q}$ is the element of the $p$-invariant $U$ corresponding to place $q$, and $M_{1}$ is the marking derived from $\mathrm{M}_{0}$ by removing one token from $q$.

Finally, place $\mathrm{p}$ from which one token is removed is a place such that:

$$
\frac{\operatorname{Var}(p)}{u_{p}}=\operatorname{Min}_{q \in E\left(M_{0}\right)} \frac{\operatorname{Var}(q)}{u_{q}}
$$

where $E\left(M_{0}\right)=\left\{p \backslash p \in P\right.$ and $\left.d f\left(M_{0}, p, C\right) \geq 1\right\}$. We notice that $E\left(M_{0}\right)$ is the set of places from which one token can be removed while keeping the solution feasible.

Criterion (18) provides a good trade off hetween a small reduction of the degree of freedom of the system and a great reduction of the value of the objective function.

If the place $p$ selected is such that $M_{0}(p)=0$, we have to find $M_{1}$ derived from $M_{0}$ by firing some transitions until $\mathrm{M}_{1}(\mathrm{p}) \geq 1$. At least one of such marking exists. The algorithm continues by replacing $\mathrm{M}_{0}$ by $\mathrm{M}_{1}$.

The algorithm stops when $E\left(M_{0}\right)=\varnothing$, i.e. when removing any of the remainder tokens would result in a non feasible marking. The AA can be summarized as follows:

1. Find a feasible marking.

2. If $E\left(M_{0}\right)=\varnothing, M_{0}$ is a solution to the problem. Stop.

3. Define $p \in E\left(M_{0}\right)$ such that:

$$
\frac{\operatorname{Var}(p)}{u_{p}}=\operatorname{Min}_{q \in E\left(M_{0}\right)} \frac{\operatorname{Var}(q)}{u_{q}}
$$

4. If $M_{0}\left(p^{*}\right) \geq 1$, set $M_{0}\left(p^{*}\right)=M_{0}\left(p^{*}\right)-1$ and $M_{0}(p)=M_{0}(p)$ for $p \in P$ and $p \neq p^{*}$.

Otherwise, find $M_{1}$ derived from $M_{0}$ by fining some transitions and such that $M_{1}\left(p^{*}\right) \geq 1$, set $M_{0}\left(p^{*}\right)=M_{1}\left(p^{*}\right)-i$ and $M_{0}(p)=M_{1}(p)$ for $p \in P$ and $p \neq p^{*}$.

5. Go to 2 .

Usually, the initial feasible solution $M_{0}$ is chosen as $M_{0}(p)=1$ for any $p \in P$. This marking was proven to be feasible as soon as $C \geq \operatorname{Max} \theta_{t}$.

The AA has been proven to be very efficient in the sense that it provides solutions very close to the optimum and, in several cases, equal to the optimum.

\section{b. Using the AA to compute the upper bound}

As stated in the previous section, an upper bound is computed for each node of the B\&B tree. Thus, we have to take into account the fact that some of the places of the extended model are 
already marked.

Note that the B\&B approach is based on the extended model. We also notice that at node $w$ of the $B \& B$ tree, the marking $M_{0}(p)$ has been determined for any place $p \in P^{f}(w)$. We apply the $A A$ algorithm to the extended model to obtain an upper bound by starting from the initial marking $M_{w}$ defined as follows:

$$
M_{w}(p)=\left\{\begin{array}{l}
M_{0}(p) \text { if } p \in P^{f}(w) \\
1 \text { otherwise }
\end{array}\right.
$$

$\mathbf{M}_{\mathrm{w}}$ is a feasible marking if problem $\boldsymbol{P}_{3}$ has a solution when taking into account markings $\mathrm{M}_{0}(\mathrm{p}) \forall \mathrm{p} \in \mathrm{Pf}^{\mathrm{f}}(\mathrm{w})$ and when relaxing the integrity constraint of $\mathrm{M}_{0}(\mathrm{p}) \forall \mathrm{p} \notin \mathrm{Pf}(\mathrm{w})$. In other words, $\mathrm{M}_{\mathrm{W}}$ is feasible if the lower bound presented in the next section is found.

\section{COMPUtation OF THE Lower BOUND}

A lower bound is computed for each node $w$ of the B\&B tree. To reach this goal, we first solve a relaxed LP problem $\mathbf{P} *(w)$ derived from $\boldsymbol{P}_{3}$. We then use the properties established hereafter to obtain additional constraints from the solution of $\boldsymbol{P} *(w)$. We denote by $\mathbf{P} * *(w)$ problem $\mathcal{P}^{*}(w)$ completed by these new constraints. The solution of $\mathcal{P}^{* *}(w)$ provides the desired lower bound.

\section{a. Problem $\mathcal{P} *(w)$}

Problem $\boldsymbol{P}^{*}(w)$ is formulated as follows:

$$
\text { Minimize } \sum_{p \in P} u_{p} x_{p}
$$

s.t.

$$
\begin{aligned}
& \theta_{o p} \leq S_{p^{o}}(1)-S_{O p^{\prime}}(1)+C\left(x_{p}+x_{p^{\prime}}\right)<C+\theta_{o p^{\prime}}, \forall p \in P_{0} \\
& S_{t}(1) \in\left(-\theta_{t}, C-\theta_{t}\right], \forall \cdot t \in T_{0} \\
& x_{p}=M_{0}(p), \forall p \in P^{f}(w) \\
& 0 \leq x_{p} \leq 1, \forall p \in P \backslash P^{f}(w)
\end{aligned}
$$

Clearly, $\mathbf{P}^{*}(\mathrm{w})$ is not different from problem $\boldsymbol{P}_{3}$ except that the markings of places $\mathrm{p} \in \mathrm{Pf}_{(\mathrm{w})}$ are given and that the markings for the other places are supposed to be real numbers.

\section{b. Introducing new constraints to problem $\mathbf{P} *(w)$}

$b_{1}$. If variables $x_{p}$ represent the number of tokens in place $p$ of the initial model (i.e. the total number of tokens in place $p$ and the place $p^{\prime}$ comesponding to $p$ in the extended model), then a 
necessary and sufficient condition to obtain a cycle time of the system less than $\mathrm{C}$ is:

$$
\sum_{p \in \gamma} x_{p} \geq\left\lceil\frac{\sum_{t \in \gamma} \theta_{t}}{C}\right\rceil \forall \gamma \in \Gamma
$$

where $\Gamma$ is the set of elementary circuits of the initial EG model.

Thus, adding constraints (24) to problem $\mathcal{P} *(w)$ would improve the lower bounds. Unfortunately, the number of elementary circuits is too big to introduce constraints (24) for all of them. We thus use the solution of $\boldsymbol{P} *(w)$ to select the constraints which are the most interesting to improve (i.e. increase) the lower bound. Using relations (20), it is easy to prove that:

$$
\sum_{\mathrm{p} \in \boldsymbol{\gamma}} \mathrm{x}_{\mathrm{p}} \geq \frac{\sum_{\mathrm{t} \in \boldsymbol{\gamma}} \theta_{\mathrm{t}}}{\mathrm{C}}, \forall \gamma \in \Gamma
$$

where $\left\{x_{p}\right\}_{p \in P}$ is the solution of $\boldsymbol{P} *(w)$, but (24) may be violated for some of the $\gamma \in \Gamma$. The idea is thus to add to problem $\boldsymbol{P}^{*}(\mathrm{w})$ the constraints (24) which are violated by the solution of $\boldsymbol{p} *(\mathrm{w})$.

For each place $\mathrm{p} \in \mathrm{P}_{0}$, we consider the set $\Gamma_{\mathrm{p}}$ of circuits containing $\mathrm{p}$ and determining the one, denoted by $\gamma_{\mathrm{p}}$, which minimizes $\left(\sum_{\mathrm{p} \in \boldsymbol{\gamma}} \mathrm{x}_{\mathrm{p}}-\frac{1}{\mathrm{C}} \sum_{\mathrm{t} \in \boldsymbol{\gamma}} \theta_{\mathrm{t}}\right)$. This elementary circuit can be determined polynomially.

Constraints (24) related to the circuit $\gamma_{\mathrm{p}}$ are added to problem $\boldsymbol{P} *(w)$.

b2. Constraints (24) concern the elementary circuits. The constraints introduced hereafter concern the paths of the event graph. We need some preliminary results to establish these new constraints.

\section{Result 3:}

We consider a path $\sigma=\left(t_{1}, p_{1}, t_{2}, p_{2}, \ldots, t_{n-1}, p_{n-1}, t_{n}\right)$ of the event graph. In a periodic operation node, a necessary condition for the system to have a cyclic time less than or equal to $C$ is that $\sigma$ contains at least $\left\lfloor\sum_{i=2}^{n} \theta_{i \mathrm{i}} / \mathrm{C}\right\rfloor$ tokens.

Proof:

The operation node being periodic, relation (6) holds, and thus:

$$
\mathrm{S}_{\mathrm{t}_{\mathrm{i}}}(1)+\theta_{\mathrm{t}_{\mathrm{i}}} \leq \mathrm{S}_{\mathrm{t}_{\mathrm{i}+1}}(1)+\text { C. } \mathrm{M}_{0}\left(\mathrm{p}_{\mathrm{i}}\right), \text { for } \mathrm{i}=1,2, \ldots, \mathrm{n}-1
$$

By adding relations (25), we obtain: 


$$
S_{t_{1}}(1)+\sum_{i=1}^{n-1} \theta_{t_{i}} \leq S_{t_{n}}(1)+C \sum_{i=1}^{n-1} M_{0}\left(p_{i}\right)
$$

But, according to relations (8):

$$
S_{t_{n}}(1) \leq C-\theta_{t_{n}}
$$

and thus:

$$
S_{t_{1}}(1)+\sum_{i=1}^{n-1} \theta_{t_{i}} \leq C-\theta_{t_{n}}+C \sum_{i=1}^{n-1} M_{0}\left(p_{i}\right)
$$

or:

$$
S_{t_{1}}(1)+\sum_{i=1}^{n} \theta_{t_{i}} \leq C+C \sum_{i=1}^{n-1} M_{0}\left(p_{i}\right)
$$

But, according to relations (8), we also have:

$$
S_{t_{1}}(1)>-\theta_{t_{1}}
$$

thus:

$$
-\theta_{\mathfrak{i}}+\sum_{i=1}^{n} \theta_{t_{i}}<C+C \sum_{i=1}^{n-1} M_{0}\left(p_{i}\right)
$$

or:

$$
\sum_{i=2}^{n} \theta_{t_{i}}<C+C \sum_{i=1}^{n-1} M_{0}\left(p_{i}\right)
$$

This leads to:

$$
\sum_{i=1}^{n-1} M_{0}\left(p_{i}\right)>\left(\sum_{i=2}^{n} \theta_{t_{i}} / C\right)-1
$$

The $\mathrm{M}_{0}\left(\mathrm{p}_{\mathrm{i}}\right)^{\prime}$ s being integers:

$$
\sum_{i=1}^{n-1} M_{0}\left(p_{i}\right) \geq\left\lfloor\sum_{i=2}^{n} \theta_{t_{i}} / C\right\rfloor
$$

\section{Corollary}

If, in a path $\dot{\sigma}=\left(t_{1}, p_{1}, t_{2}, p_{2}, \ldots, t_{n-1}, p_{n-1}, t_{n}\right)$ of the event graph, $t_{1}$ is the transition $t_{0}$, i.e. the transition belonging to the root of the $\mathrm{B} \& \mathrm{~B}$ tree, then the number of tokens in $\sigma$ should be at least equal to $\left\lfloor\sum_{i=2}^{n} \theta_{t_{i}} / C-\varepsilon\right\rfloor$ when the operation node is periodic in order to reach a cycle time less than or equal to $C$. $\varepsilon$ is a positive real which can he as small as possible.

Proof:

If $t_{1}=t_{0}$, then $S_{t_{1}}(1)=0$, and inequality (26) becomes:

$$
\sum_{i=1}^{n} \theta_{t i} \leq C+C \sum_{i=1}^{n-1} M_{0}\left(p_{i}\right)
$$


or:

$$
\sum_{i=1}^{n-1} M_{0}\left(p_{i}\right) \geq\left(\sum_{i=1}^{n} \theta_{t i} / C\right)-1
$$

and:

$$
\sum_{i=1}^{n-1} M_{0}\left(p_{i}\right) \geq\left\lfloor\sum_{i=1}^{n} \theta_{i_{i}} / C-\varepsilon\right\rfloor
$$

Q.E.D.

The constrains related to the path are derived from Result 3, the corollary, as well as from inequalities (24).

We denote by $w$ the current node. Let us consider a place $p$ whose marking has not been decided yet, i.e. $\mathrm{p} \notin \mathrm{Pf}^{\mathrm{f}}(\mathrm{w})$. Let us also consider the marking $\mathrm{M}_{\mathrm{f}}$ with $\mathrm{M}_{\mathrm{f}}(\mathrm{p})=\mathrm{M}_{0}(\mathrm{p})$, $\forall \mathrm{p} \in \mathrm{Pf}^{\mathrm{f}}(\mathrm{w})$, and $\mathrm{M}_{\mathrm{f}}(\mathrm{p})=0, \forall \mathrm{p} \notin \mathrm{P}^{\mathrm{f}}(\mathrm{w})$. For each transition $\mathrm{t} \in \mathrm{T}$ and $\mathrm{t} \neq{ }^{\circ} \mathrm{p}$, we compute a path $\sigma_{0}\left(\mathrm{t},{ }^{\circ} \mathrm{p}\right)$ joining $\mathrm{t}$ to ${ }^{\circ} \mathrm{p}$ which

$$
\text { Maximizes } \sum_{q \in \sigma_{0}(1,0) \cap p}\left(\theta_{q^{o}}-C . M_{f}(q)\right)
$$

Notice that $\sigma_{0}\left(\mathrm{t},{ }^{\circ} \mathrm{p}\right)$ is the path among those joining $\mathrm{t}$ to ${ }^{\circ} \mathrm{p}$ in which a maximal number of tokens is needed to reach the cycle time $\mathrm{C}$ and that it can be determined polynomially.

Consider now path $\sigma(\mathrm{t}, \mathrm{p})$ obtained from $\sigma\left(\mathrm{t},{ }^{\circ} \mathrm{p}\right)$ by adding $\mathrm{p}$ and $\mathrm{p}^{0}$.

Let $\mu(t, p)$ be the number of tokens assigned to path $\sigma(t, p)$ according to the optimal solution $\left\{x_{q}\right\}_{q \in P}$ of problem $\mathbf{P} *(w)$, i.e. $\mu(t, p)=\Sigma_{q \in \sigma(t, p)} x_{q}$. Let:

$$
\Delta(\mathrm{t}, \mathrm{p})=\left\{\begin{array}{l}
{\left[\sum_{\mathrm{i}=1}^{\mathrm{n}} \theta_{\mathrm{t}_{\mathrm{i}}} / \mathrm{C}\right]-\mu(\mathrm{t}, \mathrm{p}) \text { if } \sigma(\mathrm{t}, \mathrm{p}) \text { is an elementary circuit }} \\
\left\lfloor\sum_{\mathrm{i}=2}^{\mathrm{n}} \theta_{\mathrm{t}_{\mathrm{i}}} / \mathrm{C}\right\rfloor-\mu(\mathrm{t}, \mathrm{p}) \text { if } \sigma(\mathrm{t}, \mathrm{p}) \text { is not a circuit and } \mathrm{t} \neq \mathrm{t}_{0} \\
\left\lfloor\sum_{\mathrm{i}=1}^{\mathrm{n}} \theta_{\mathrm{t}_{\mathrm{i}}} / \mathrm{C}-\varepsilon\right\rfloor-\mu(\mathrm{t}, \mathrm{p}) \text { if } \sigma(\mathrm{t}, \mathrm{p}) \text { is not a circuit and } \mathrm{t}=\mathrm{t}_{0}
\end{array}\right.
$$

$\Delta(t, p)$ is the minimal number of tokens which should he introduced in $\sigma(t, p)$ to meet the necessary condition for the system to reach a cycle time less than or equal to $\mathrm{C}$.

We then define $t^{*}$ such that:

$$
\Delta\left(\mathrm{t}^{*}, \mathrm{p}\right)=\underset{\mathrm{t} \in \mathrm{T}}{\operatorname{Max}} \Delta(\mathrm{t}, \mathrm{p})
$$

$\sigma\left(t^{*}, p\right)$ is the path which ends up at $\mathrm{p}^{0}$ and to which the larger number of tokens should be added to reach a cycle time less than or equal to $C$.

Finally, for each $\mathrm{p} \notin \mathrm{Pf}^{\mathrm{f}}(\mathrm{w})$, we introduce the following constraint:

$$
\sum_{\mathrm{q} \in \sigma\left(\mathrm{t}^{*}, \mathrm{p}\right) \cap \mathrm{p}} \mathrm{x}_{\mathrm{q}} \geq \mu\left(\mathrm{t}^{*}, \mathrm{p}\right)+\Delta\left(\mathrm{t}^{*}, \mathrm{p}\right) \text { for } \mathrm{p} \notin \mathrm{P}^{\mathrm{f}}(\mathrm{w})
$$

$\mathbf{P}^{* *}(\mathrm{w})$ is obtained by adding to $\mathbf{P}^{*}(\mathrm{w})$ constraints $(24)$ and $(26)$ as explained in this section. The solution of $\mathbf{P}^{* *}(w)$ is the lower bound comesponding to node $w$. 
If either $\mathcal{P} *(w)$ or $\mathcal{P} * *(w)$ has no solution, the node $w$ cannot lead to an optimal solution of the problem at hand, and no further computation is made starting from $w$.

\section{THE B\&B ALGORITHM}

The $\mathrm{B} \& \mathrm{~B}$ algorithm is summarized hereafter.

1. Select to as shown in Subsection (3.a).

2. Order the set of places (see Subsection 3.b).

3. Create the root by setting $M_{0}(p)=1$ for $p \in{ }^{\circ} t_{0}$, and denote this root by $w$.

4. Compute the lower bound $\mathrm{lb}(w)$ at node $w$ by:

- solving $\mathbf{P} *(w)$,

- creating the additional constraints,

- solving $\mathcal{P} * *(\mathbf{w})$,

as shown in Section 6 .

5. If either $\boldsymbol{P}^{*}(w)$ or $\boldsymbol{P}^{* *}(w)$ does not have solution, remove $w$ from the set $\mathcal{N}$ of pending nodes and go to step 8 .

6. Compute the upper bound at node $w$ (see Section 5) and denote by $u b(w)$ the smallest upper bound obtained at this point.

7. If $\mathrm{lb}(\mathrm{w})>\mathrm{ub}(\mathrm{w})$, remove $w$ from the set $\mathcal{N}$ of pending nodes.

Otherwise:

(i) if $w$ has two descendants, compute them and add them to the set $\mathcal{N}$ of pending nodes, otherwise keep the solution corresponding to $w$ if it is the first solution obtained, or if this solution is better than any of the solutions obtained previously,

(ii) remove $w$ from the set $\mathcal{N}$ of pending nodes.

8. If $\mathcal{N} \neq \varnothing$, choose one $w \in \mathcal{N}$ and go to step 4 , otherwise print the best solution obtained and stop the computation.

\section{Application to the Design of an fMS}

In this section, we apply the above algorithm to the design of an FMS.

\section{a. Introduction of the problem}

The FMS at hand is composed of four machines $\mathrm{M}_{1}, \mathrm{M}_{2}, \mathrm{M}_{3}$ and $\mathrm{M}_{4}$. It can produce three types of products denoted by $T_{1}, T_{2}$ and $T_{3}$. The manufacturing processes of these product types are given in Figure 3. The numbers in parentheses are the manufacturing times. 
We neglect the transportation times for simplicity, but taking into account the transportation times would not modify the approach presented hereafter.

We assume that the production ratios considered in the current scenario are $1 / 4,1 / 4$ and $1 / 2$ for $T_{1}, T_{2}$ and $T_{3}$, respectively.

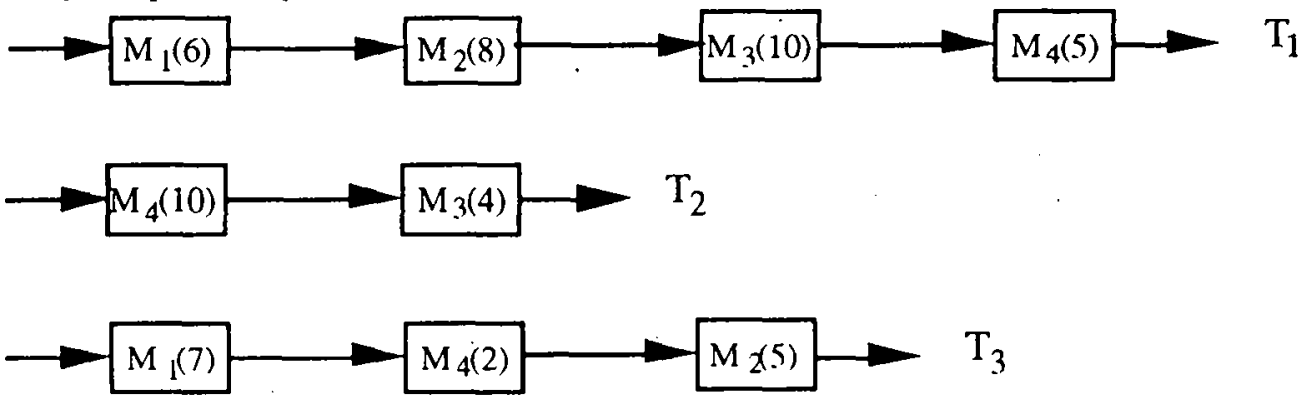

Fig. 3: Manufacturing processes of the product types

The goal is to reach a given productivity using a number of AGVs which is as small as possible.

The input sequences of the machines, which verify the production ratios, are:

$$
\begin{aligned}
& \text { for } M_{1}: T_{1}, T_{3}, T_{3} \\
& \text { for } M_{2}: T_{1}, T_{3}, T_{3} \\
& \text { for } M_{3}: T_{1}, T_{2} \\
& \text { for } M_{4}: T_{1}, T_{2}, T_{3}, T_{3}
\end{aligned}
$$

The time necessary to manufacture a complete sequence which fits with the required ratios, say $\mathrm{T}_{1}, \mathrm{~T}_{2}, \mathrm{~T}_{3}, \mathrm{~T}_{3}$, is:

$$
\begin{aligned}
& \text { for } M_{1}: 6+2 \times 7=20 \\
& \text { for } M_{2}: 8+2 \times 5=18 \\
& \text { for } M_{3}: 10+4=14 \\
& \text { for } M_{4}: 5+10+2 \times 2=19
\end{aligned}
$$

We know (see [4]) that it is always possible to fully utilize the bottle-neck machine, which is $M_{1}$ in this case. In other words, it is always possible to manufacture a sequence $T_{1}, T_{2}, T_{3}, T_{3}$ in steady state in a cycle time of length $C=20$. The goal is to reach this goal with a number of AGVs which is as small as possible.

\section{b. Modelling}

The way to model a manufacturing system whose operation mode is periodic was extensively explained in [4] and [5]. The model corresponding to the example considered in this section in given in Figure 4.

This model is an event graph which exposes three types of elementary circuits which are:

(i) The process circuits, which model the manufacturing processes. For instance $<t_{1}$, $\mathrm{p}_{2}, \mathrm{t}_{2}, \mathrm{p}_{3}, \mathrm{t}_{3}, \mathrm{p}_{4}, \mathrm{t}_{4}, \mathrm{p}_{1}, \mathrm{t}_{1}>$ is a process circuit. These circuits model the physical part of the system, and the tokens which bolong to these circuits represent AGVs; 


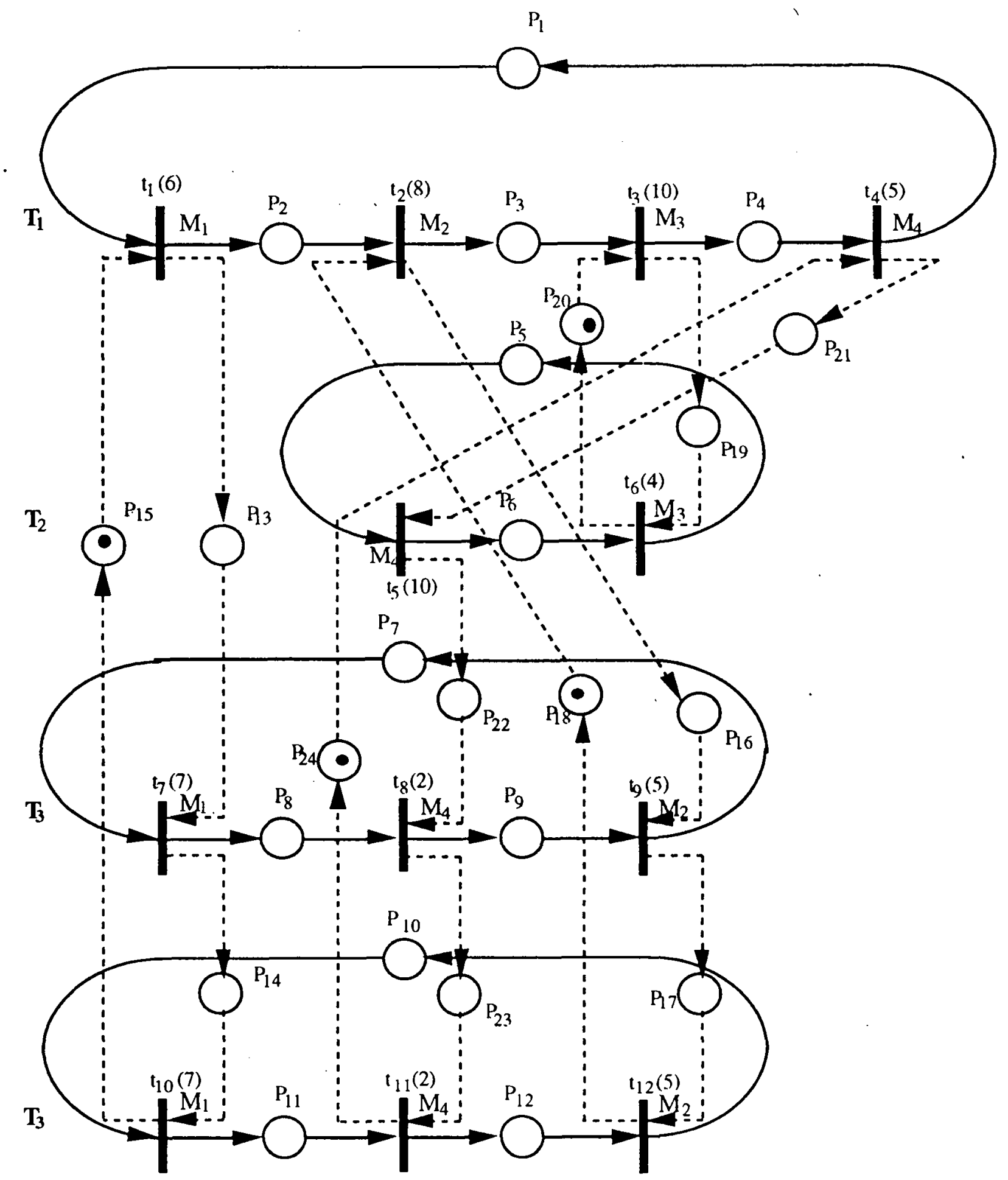

Fig. 4: The event glaph model of the FMS

(ii) The command circuits, which model the control of the system. One command circuit is associated to each machine. For instance $\left\langle\mathrm{p}_{15}, \mathrm{t}_{1}, \mathrm{p}_{13}, \mathrm{t}_{7}, \mathrm{p}_{14}, \mathrm{t}_{10}, \mathrm{p}_{15}\right\rangle$ is a command circuit. There is exactly one token in each command circuit, which prevents two transitions corresponding to the same machine to be fired simultaneously. This token represents information; 
(iii) The mixed circuits, partially composed of parts of the command circuits, and partially of parts of the process circuits. For instance $<t_{11}, p_{24}, t_{4}, p_{1}, t_{1}, p_{13}, t_{7}, p_{14}, t_{10}, p_{11}$, $t_{11}>$ is a mixed circuit. The number of mixed circuits is usually very high even for quite small models.

\section{c. Problem formulation and solution}

The p-invariant used to minimize the number of $A G V s$ is the vector $t U=\left[u_{1}, u_{2}, \ldots, u_{24}\right]$ such that:

$$
u_{i}= \begin{cases}1 & \text { if } i=1,2, \ldots, 12 \\ \alpha & \text { if } i=13,14, \ldots, 24\end{cases}
$$

We choose $\alpha=10^{4}$ in order to limit to 1 the number of tokens in the command circuits, as required by the model.

Furthermore $\mathrm{C}=20$.

Any transition can be chosen as transition $t_{0}$ since each $t \in T$ has one input place belonging to a command circuit and one output place belonging to a process circuit. We choose $t_{0}=t_{1}$. Thus, $\mathrm{M}_{0}\left(\mathrm{p}_{1}\right)=\mathrm{M}_{0}\left(\mathrm{p}_{15}\right)=1$.

The places are ordered as follows:

- places belonging to command circuits are ordered first: $p_{13}, p_{14}, \ldots, p_{24}$;

- then places belonging to process circuits follow: p $_{2}, \mathrm{p}_{3}, \ldots, \mathrm{p}_{12}$.

The places used to build the extended model (which is not represented) follow place $\mathrm{p}_{12}$.

In this example, the algorithm created 16 levels (i.e. examined 16 nodes, including the root). The final result is:

$$
M_{0}=(0,1,1,1,1,0,1,0,0,1,0,0,1,0,0,0,0,1,0,1,0,0,0,1)
$$

We thus need three tokens in the process circuit corresponding to $T_{1}$, one token in the process circuit corresponding to $T_{2}$ and one in each of the process circuits corresponding to $T_{3}$.

Thus, assuming that each AGV carries one product, we need 6 AGVs if we want to manufacture a set $\left(T_{1}, T_{2}, T_{3}, T_{3}\right)$ in steady state during each period of 20 units of time. The algorithm also provides the initial location of the AGVs, which means that, in transient state, we may have to let some AGVs unloaded during some periods, until the steady state is reached.

\section{CONCLUSION}

This paper provides a Branch-and-Bound approach to define the minimal number of AGVs to be used in order to reach a given productivity. Extended numerical experiences conducted by Sauer [9] show that event graph models with one hundred places and one hundred transitions can be solved, which corresponds to the size of common Flexible Manufacturing Systems.

Further research should concern the improvement of the Iower bounds by finding new 
properties of the optimal solution. We should also find a way to mark several places at each iteration of the Branch-and-Bound algorithm.

\section{BIBLIOGRAPHY}

[1] G.W. BRAMS, "Réseaux de Petri : Théorie et Pratique", Masson, Paris, France, 1983.

[2] P. CHRETIENNE. "Les Réseaux de Petri Temporisés", Thèse d'Etat, Université Pierre et Marie Curie (Paris VI), Paris, France, June 1983.

[3] F. COMMONER, A. HOLT, S. EVEN et A.PNUELI, "Marked Directed Graphs", Journal of Computer and System Science, Vol. 5, No. 5, 1971.

[4] H.P. HILLION et J.M. PROTH, "Performance Evaluation of Job-shop Systems using Timed Event Graphs", IEEE Transactions on Automatic Control, Vol. 34, No. 1, pp. 3-9, January 1989.

[5] S. LAFTIT, J.M. PROTH et X.L. XIE, "Optimization of Invariant Criteria for Event Graphs", IEEE Transactions on Automatic Control, Vol. 37, No. 5, p. 547-555, 1992.

[6] T. MURATA, "Petri Nets: Properties, Analysis and Applications", Proceedings of the IEEE, Vol. 77, No. 4, September 1982.

[7] C.V. RAMAMOORTHY et G.S. HO, "Performance Evaluation of Asynchronous Concurrent Systems Using Petri Nets", IEEE Trans. on Software Engineering, Vol. SE-6, No. 5, 1980.

[8] C. RAMCHANDANI, "Analysis of Asynchronous Concurrent Systems Using Petri Nets", Rapport technique ${ }^{\circ} 120$, Laboratory for Computer Science, MIT, Cambridge, MA, 1974.

[9] N. SAUER, "Les Graphes d'Evénements Stochastiques et leur Utilisation pour l'Evaluation des Systèmes de Production", Thèse de Doctorat, Université de Metz, France, September 1994. 


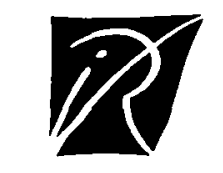

Unité de recherche INRIA Lorraine

Technopôle de Nancy-Brabois - Campus scientifique

615 , rue du Jardin Botanique - B.P. 101 - 54602 Villers lès Nancy Cedex (France)

Unité de recherche INRIA Rennes - IRISA, Campus universitaire de Beaulieu 35042 Rennes Cedex (France) Unité de recherche INRIA Rhóne-Alpes - 46, avenue Félix Viallet - 3803I Grenoble Cedex 1 (France)

Unité de recherche INRIA Rocquencourt - Domaine de Voluceau - Rocquencourt - B.P. 105 - 78153 Le Chesnay Cedex (France)

Unité de recherche INRIA Sophia Antipolis - 2004, route des Lucioles - B.P. 93-06902 Sophia Antipolis Cedex (France)

Éditcur

INRIA - Domaine de Voluceau - Rocquencourt - B.P. 105 - 78153 Le Chesnay Cedex (France)

ISSN $0249-6399$ 